\title{
Infância na casa de acolhimento no contexto prisional: um olhar sobre o crescimento e desenvolvimento
}

\author{
Children in the welcoming house in the prisonal context: \\ a look at growth and development
}

\author{
Denise Santana Silva dos Santos' ${ }^{1}$, Tânia Christiane Ferreira Bispo ${ }^{2}$, Sara Moreira dos Santos ${ }^{3}$ \\ Fabiane Nunes ${ }^{4}$, Letícia Rebouças ${ }^{5}$, Climene Laura de Camargo ${ }^{6}$ \\ 'Departamento de Ciências da Vida, Universidade do Estado da Bahia. Salvador, Bahia, Brasil. denisenegal@hotmail.com \\ ${ }^{2}$ Departamento de Ciências da Vida, Universidade do Estado da Bahia. Salvador, Bahia, Brasil. taniaenf@uol.com.br \\ 3Universidade do Estado da Bahia. Salvador, Bahia, Brasil.sarynhams@hotmail.com \\ ${ }^{4}$ Escola Bahiana de Medicina e Saúde Pública. Salvador, Bahia, Brasil. fabianenunes@hotmail.com.br \\ 5Universidade Federal da Bahia. Salvador, Bahia, Brasil. lele-tannus@hotmail.com \\ ¿Universidade Federal da Bahia. Salvador, Bahia, Brasil. climenecamargo@hotmail.com
}

\begin{abstract}
RESUMO | Objetivo: Avaliar o crescimento e desenvolvimento nos aspectos, psicomotores e cognitivos nas crianças filhas de mães em situação de prisão que vivem em uma creche. Método: Estudo de campo de caráter descritivo e abordagem qualitativa. Participaram da pesquisa 09 crianças da casa de acolhimento Nova Semente, extensão do complexo Penitenciário Lemos de Brito alocado na cidade de Salvador - BA no mês de maio de 2016. Resultados: Entre as crianças, $54,6 \%$ eram do sexo feminino e $63,6 \%$ estavam na faixa etária entre 24 a 72 meses. Percebeu-se que todas as crianças apresentaram estatura adequada para a idade. Assim como, 100\% apresentaram percentil nutricional dentro da normalidade. Algumas crianças encontravam-se com o desenvolvimento afetado, revelado pelo atraso na leitura, contagem de numerais, identificação de cores, além do atraso social. Conclusão: Esses resultados mostram a necessidade da atuação da equipe multidisciplinar que assistem essas crianças para promoverem estratégias que aprimorem a assistência frente o seu desenvolvimento.
\end{abstract}

\begin{abstract}
I Objective: To evaluate the growth and development in the psychomotor and cognitive aspects in the children of pregnant mothers living in a day care center. Method: descriptive field study and qualitative approach. The participants were 09 children of the host home New Seed, complex extension Lemos Brito Penitentiary allocated in the city of Salvador - BA in May 2016. Results: Among the children, 54.6\% were female and $636 \%$ were aged between 24 to 72 months. It was noticed that all the children had adequate height for age. As well as, $100 \%$ had nutritional percentile normal. Some children were affected with the development, revealed the delay in reading, numerals count, color identification, in addition to social backwardness. Conclusion: These results show the need for health professionals who assist these children promote strategies that enhance its development assistance front.
\end{abstract}

Keywords: Child development; Prisons; Child.

Descritores: Desenvolvimento infantil; Prisões; criança. 


\section{Introdução}

A população feminina brasileira vem aumentando notavelmente no contexto prisional. Segundo os dados do Infopen, entre 2000 e 2014, houve um crescimento de $567 \%$ desse público, tornando-se a quinta maior população carcerária feminina do mundo (Ministério da Justiça, 2014). Esses dados ainda revelam que a maioria dessas mulheres se encontra no período fértil, e consequentemente leva ao aumento no número de crianças no contexto prisional.

Diante da sociedade e das autoridades governamentais a realidade de crianças do contexto carcerário é uma questão polêmica. A prole das mulheres em situação de prisão sempre enfrentou sérias dificuldades no que diz respeito à estrutura, alimentação, ao sócio cognitivo e afetivo dentro do ambiente prisional. $O$ aumento no número de crianças no sistema prisional gera consequências de várias ordens, entre elas a fragilização do vínculo do binômio (Bruscato, 2011 ).

A infância se caracteriza por uma etapa da vida que vai do nascimento à adolescência, e que, segundo as características anatômicas, fisiológicas e psíquicas, se divide em três estágios: primeira infância, zero a três anos; segunda infância, de três a sete anos; e terceira infância, de sete anos até a puberdade.

Após a promulgação da Lei 9.046 de 18 de maio de 1995, é direito assegurado das mães privadas de liberdade, condições para que possam permanecer com seus filhos durante os 6 primeiros meses de amamentação. Após este período, é determinada a separação do binômio mãe-filho, todavia a criança possui três possibilidades para ser encaminhada: instituição de abrigo, em família substituta (que pode ser a sua família ampliada) ou berçário e/ou creche do presídio (Stella et al., 2010). O presente artigo vai se restringir a última opção.

Conforme a Constituição Federal (art. 208) e o Estatuto da Criança e do Adolescente - ECA (art. 54) é direito da criança de 0 a 6 anos 0 atendimento em creche e pré-escola (Lei $n^{\circ} 9.394,1996$ ), sendo subdividida da seguinte forma: creches para crianças de até 3 anos e pré-escolas para crianças de 4 a 6 anos. De acordo com as características do grupo de crianças de 0 a 3 anos, deve existir a separação entre berçários e maternal. Desta forma, as atividades devem ser separadas por idade, criando um ambiente estimulador. $O$ documento do Ministério da Justiça reafirma que as crianças filhas de presidiário entre 0 e 6 anos será encaminhada para as instituições citadas acima, segundo a faixa etária. E, foi a partir da aprovação da n. Lei 11.942 , do dia 28 de maio de 2009 que houve a criação da casa de acolhimento para abrigar e dar assistência a estas crianças.

A Lei de Diretrizes e Bases da Educação estabelece que a educação infantil é a primeira etapa da educação básica e tem como finalidade o desenvolvimento integral da criança até 6 anos de idade, em seus aspectos físico, psicológico, intelectual e social, complementando a ação da família e da comunidade (Lei $n^{\circ}$ 9.394, 1996).

O Ministério da Educação define as creches e préescolas como espaços institucionais não domésticos que podem ter caráter público ou privado, que educam e cuidam de crianças de 0 a 6 anos de idade, no período diurno, em jornada integral ou parcial, regulados e supervisionados por órgão competente do sistema de ensino e sob controle social.

Frente 0 contexto de vivenciar um ambiente estranho, com pessoas nunca vistas antes e longe do seio familiar, sabe-se que estes fatores interferem tanto no crescimento quanto no desenvolvimento da criança. Com relação ao processo de crescimento, compreende-se que há dois tipos de aspectos que se embricam ao processo de crescimento, são eles: os intrínsecos (genéticos) e extrínsecos (ambientais), entre os quais se enfatizam a alimentação, a saúde, a higiene, a habitação e os cuidados integrais com a criança, que atuam acelerando ou diminuindo tal processo (Ministério da Saúde, 2002).

Habitua-se falar em desenvolvimento de forma peculiar entre desenvolvimento físico, cognitivo e psicossocial, para desta maneira facilitar o entendimento do estudo do desenvolvimento humano. Mas, sabe-se que tais conceitos estão interligados e influenciam-se mutuamente durante a vida da pessoa (Ministério da Saúde, 2002). 
Partiu-se da hipótese de que as crianças no contexto prisional têm seu crescimento e desenvolvimento prejudicado, principalmente pelo distanciamento da família e dificuldade dos profissionais que lhes assistem conseguir alcançar e suprir as necessidades de todas as crianças.

Justifica-se a importância da realização do estudo porque $\circ$ crescimento e desenvolvimento infantil refletem de maneira significativa no futuro das crianças. Deste modo, formulou-se a seguinte questão norteadora: De que maneira se dá o crescimento e desenvolvimento das crianças no contexto prisional?

Portanto, o objetivo geral desse artigo é: Avaliar o crescimento e desenvolvimento em seus múltiplos aspectos psicomotores e cognitivos, das crianças filhas de mães em situação de prisão que vivem em uma creche. E, como objetivos Específicos: Caracterizar o perfil destas crianças e comparar o desenvolvimento destas crianças com a literatura.

\section{Métodos}

Estudo de campo, de caráter descritivo e abordagem qualitativa, realizado na casa de acolhimento Nova Semente, extensão do complexo Penitenciário Lemos de Brito alocado na cidade de Salvador - BA. A população foi constituída por 09 crianças que residiam nesta instituição no período da pesquisa.

A população-alvo foi composta por crianças que atenderam aos seguintes critérios de inclusão: estar na faixa de 6 meses a 9 anos e que não são portadoras de doenças que comprometam seu crescimento e desenvolvimento. Todas as crianças atenderam a esses critérios.

A coleta de dados foi realizada no mês de maio de 2016 utilizando um instrumento semi-estruturado por meio de entrevista, elaborado com base no manual do Ministério da Saúde. A análise dos dados foi realizada de maneira descritiva, sendo apresentados por meio de tabelas e fundamentados na literatura.

Para o levantamento bibliográfico fez-se uso da Biblioteca Virtual de Saúde - BVS. Utilizaram-se os seguintes descritores na língua portuguesa: criança institucionalizada, crescimento e desenvolvimento, presídio. Todos os artigos foram acessados na íntegra.

Após contato estabelecido com os responsáveis da instituição, foi explicado de forma minuciosa o projeto, os indivíduos interessados em participar foram registrados como voluntários na medida em que consentiam e formalizaram a intenção através do Termo de Assentimento Livre e Esclarecido - TALE.

A pesquisa é um recorte do projeto maior intitulado: "Nascer e crescer atrás das grades: um olhar sobre a criança e o adolescente no contexto prisional". Esta pesquisa foi submetida através da Plataforma Brasil e aprovada pelo Comitê de Ética em Pesquisa - CEP/UNEB CAAE: 49996915.4.0000.0057 para o seu desenvolvimento através do parecer de número 1.333.685.

Por se tratar de uma pesquisa envolvendo seres humanos, a mesma está de acordo com a Resolução $\mathrm{N}^{\circ}$ 466/12 do Conselho Nacional de Saúde. Foi solicitada autorização da instituição responsável por essas crianças, garantindo sua autonomia através do Termo de Consentimento Livre e Esclarecido (TCLE).

A coleta de dados ocorreu por meio de entrevista semi-estruturada. Foram utilizados 8 tipos de formulários, elaborados de acordo com a faixa etária da criança, segundo o caderno de atenção básica, $n^{\circ} 33$ - Saúde da criança: crescimento e desenvolvimento. A criança respondeu apenas - correspondente com a sua faixa etária. Os formulários foram divididos da seguinte maneira: Crianças de 6 a 9 meses, $>9$ a 12 meses, $>12$ a 15 meses, $>15$ meses a 2 anos, $>2$ a 3 anos, $>3$ a 4 anos, $>4$ a 6 anos, $>6$ a 9 anos. Todos eles são compostos por dados de identificação da criança: Sexo, idade, dados antropométricos: peso, estatura, IMC e se diferem por questões sobre características próprias relacionadas ao desenvolvimento da criança de acordo com a faixa etária.

O material empírico foi analisado segundo a perspectiva da análise de conteúdo de Bardin que consiste em um conjunto de técnicas de análises das comunicações que utiliza procedimentos sistemáticos e objetivos de descrição do conteúdo das mensagens 
(Bardin, 2011 1). Foram utilizadas as seguintes etapas: pré-análise, exploração do material, tratamento de resultados e codificação.

Em linhas gerais, na análise de conteúdo os (as) pesquisadores (as) estabelecem categoriais e depois contabilizam as incidências em cada categoria. Dessa maneira, por meio da contagem do uso de palavras, a análise de conteúdo consegue validar seus achados ao mesmo tempo em que torna confiáveis suas medidas (Silverman, 2009).

\section{Resultados e discussão}

\section{Perfil das crianças}

Foram analisadas 09 crianças abrigadas, na faixa etária de 6 meses a 9 anos, que não possuíam doença que afetasse seu crescimento e desenvolvimento. A tabela 1 mostra duas características predominantes: sexo feminino $(55,6 \%)$ e faixa etária entre 24 a 72 meses $(66,7 \%)$.

Tabela 1. Caracterização das crianças quanto ao sexo e idade. Salvador-Ba, 2016.

\begin{tabular}{ccc}
\hline & $\mathbf{N}=09$ & $\%$ \\
\hline Sexo & 5 & 55,6 \\
$\mathrm{~F}$ & 4 & 44,4 \\
\hline $\mathrm{I}$ & & \\
\hline Idade & 0 & 0 \\
6 a 12 meses & 1 & 11,1 \\
12 a 24 meses & 6 & 66,7 \\
$>24$ meses a 72 meses & 2 & 22,2 \\
7 a 9 anos &
\end{tabular}

\section{Avaliação do crescimento}

O crescimento infantil é avaliado seguindo os parâmetros do aumento do corpo, finalizando no aumento da estatura. Deste modo, para avaliar o crescimento em crianças a partir de 24 meses é necessário mensurar, relacionar e acompanhar peso e estatura (Ministério da Saúde, 2002).

De acordo com a tabela 2, pode-se visualizar que todas as crianças (100\%) estavam com o peso adequado para a idade, diferente do estudo com crianças institucionalizadas em Fortaleza-Ba, que mostrou crianças com baixo peso e sobrepeso (Chaves, Lima, Mendonça, Custódio, \& Matias, 2013).

Tabela 2. Caracterização das crianças quanto ao percentil do peso/idade. Salvador-Ba, 2016.

\begin{tabular}{l|l|l}
\hline Peso e Idade & $\mathbf{N}=\mathbf{0 9}$ & $\%$ \\
\hline$<$ Percentil 0,1 & 0 & 0 \\
\hline $0,1<$ Percentil < 1 & 0 & 0 \\
\hline $3<$ Percentil < 10 & 0 & 0 \\
\hline $3<$ Percentil $<97$ & 09 & 100 \\
\hline$>$ Percentil 97 & 0 & 0 \\
\hline
\end{tabular}

Estudos no ramo da epidemiologia referente ao estado nutricional revelam que uma maior atenção ao peso e o índice de massa corporal (Araújo, Hallal, Nader, Menezes, \& Victora, 2008). Atualmente no Brasil, a estatura representa um parâmetro mais importante no quadro epidemiológico da desnutrição (Romani \& Lira, 2004).

Referente a relação estatura/idade percebeu-se que todas as crianças apresentam estatura adequada para a faixa etária. Assim como, 100\% apresentam percentil de normalidade nutricional. Deste modo, é perceptível que a casa de acolhimento proporciona uma adequada assistência frente o crescimento destas crianças. 
Tabela 3. Caracterização das crianças quanto ao percentil estatura/idade e percentil peso/estatura. Salvador-Ba, 2016.

\begin{tabular}{l|c|c}
\hline & $\mathbf{N}=09$ & $\%$ \\
\hline Estatura/idade & & 0 \\
$<$ percentil 3 & 0 & $100 \%$ \\
$3<$ percentil <97 & 09 & \\
Peso/Estatura & 0 & 0 \\
$<$ percentil 3 & 09 & $100 \%$ \\
$3<$ percentil < 97 & 0 & 0 \\
> ou igual percentil 97 & & \\
\hline
\end{tabular}

\section{Avaliação do desenvolvimento}

Costuma-se falar em desenvolvimento de forma distinta entre desenvolvimento físico, cognitivo e psicossocial, como uma forma de facilitar o estudo do desenvolvimento humano. Mas cabe apontar que tais aspectos estão interligados e influenciam-se mutuamente durante a vida do indivíduo (Ministério da Saúde, 2002).

A única criança com 2 anos soube dizer o nome completo. Com relação a identificação de objetos a mesma soube identificar corretamente todos objetos que the foi apresentado. Quando observada, foi perceptível que ela sabe correr e sobir escadas. Pronuncia frases e relata também gostar de brincar com as outras crianças.

Durante os dois primeiros anos, um aspecto importantíssimo do seu desenvolvimento é o desenvolvimento afetivo, caracterizado no apego, que é o vínculo afetivo básico. A criança estabelece o vínculo com as pessoas que interagem com ela de forma privilegiada, com características de condutas, representações mentais e sentimentos (Ministério da Saúde, 2002).

Todas as crianças com idade de 3 a 3 anos e 11 meses não sabem contar de 1 a 10 . Relataram que gostam de brincar com as demais crianças. Identificam as cores, exceto uma que não soube fazer a identificação corretamente.

O processo de aprendizagem da criança envolve 0 contexto em que a mesma está inserida (Barbosa, 2017). E se tratando do desenvolvimento no sentido de número, fatores como, experiência individual, suas idéias e trocas de informações, interferem na aprendizagem da contagem.

Esta realidade no contexto prisional é bastante limitada, pois sua organização e $\circ$ quantitativo de crianças não permitem que cada uma seja alcançada de maneira completa, com vista no seu desenvolvimento. $O$ processo da construção da definição e capacidade numérica da criança é gradativo, exclusivo e varia de uma para a outra (Barbosa, 2017).

As crianças de 4 a 6 anos quando proposto que contassem ou inventassem uma história, apenas 2 souberam contar. Duas crianças desta faixa etária não falam de forma clara e compreensível. Quando questionadas quanto possuir amigos, todas relataram ter amigos de ambos os sexos, apenas uma relatou ter amigos apenas do sexo feminino e disse o seguinte "Só na casa de minha mãe" (K.P.P).

Estudo realizado com cuidadoras, revelou que na teoria as creches têm o objetivo de assistir a criança em toda sua integralidade, entretanto, na prática a assistência visa apenas os aspectos da sobrevivência física, esquecendo-se do desenvolvimento social e intelectual (Magalhães, Costa, \& Cavalcante, 2011).

As crianças com idade de 7 a 9 anos quando questionadas sobre $\circ$ que é mais interessante: seus amigos da escola ou as atividades da creche referiram as atividades da creche. Quando thes propomos falarem sobre si, relataram o seguinte: "Tenho cinco irmãos, gosto de andar de bicicleta e patins" (A.V.P.S.). Neste relato, a criança refere à integrantes da família, os irmãos, para falar sobre si. 
A família é a base da construção social. A família é então considerada um dos mais influentes grupos constitutivos do desenvolvimento humano e também principal fonte de saúde (Quintino, 2005). Mas, quando esta não se constitui de uma unidade de experiência, de aprendizagem e de criatividade, poderá se tornar um fator de doença (Hasson \& Meleiro, 2003).

O relato de K.P.S evidencia que as crianças enfrentam situações de agressão e vinculação afetiva dentro da creche. Como traz KPS em sua fala:

"Eu gosto de ajudar as tias... Ajudo... Tia posso lavar os pratos? Eu me sinto boa".

"Eu não gosto que as pessoas fiquem me batendo. Ah! Eu não gosto que as pessoas fiquem me xingando. Não gosto que fiquem batendo em F".

No que se trata a agressão física, estudos afirmam que estas crianças tendem ser agressivas, pela carência que é consequiência do abandono e de serem institucionalizadas (Oliveira \& Próchno, 2010). No estudo com cuidadoras de uma instituição, revelam que $71,57 \%$ das crianças apresentam comportamento agressivo com os colegas e adultos (Magalhães, Costa, \& Cavalcante, 2011).

Referente à vinculação afetiva que estas crianças têm pelas outras, mostrando zelo, como se fossem irmão, pôde ser observado também no estudo de Alexandre e Vieira, com crianças institucionalizadas em que as mesmas demonstraram preocupação com as outras (Alexandre \& Vieira, 2004). O fato de viverem juntas, compartilhando brinquedos, quarto, roupas e afeto lhes permitem considerar que 0 outro é seu irmão 16. Santos afirma que não há uma instituição de qualidade e ideal que possa preencher - vazio afetivo das crianças institucionalizadas (Santos, 2000).

As questões relacionadas à família, agressão física e vinculação afetiva, interferem diretamente no desenvolvimento social, cognitivo e afetivo das crianças.

\section{Considerações finais}

Foi possível perceber nesta pesquisa, um crescimento satisfatório das crianças que vivem na casa de acolhimento com base no que preconiza o Ministério da Saúde. Das crianças avaliadas todas estavam com tamanho adequado comparadas com outras crianças que vivenciam a experiência de casa de acolhimento e se comparada às crianças que vivem no contexto familiar.

Entretanto, com relação ao desenvolvimento infantil todas as crianças apresentavam seu desenvolvimento comprometido, o que foi revelado no atraso em desenvolver a leitura, contagem de numerais, identificação de cores, além do atraso social.

Diante disto, é necessário que a equipe de saúde promova uma melhora na assistência frente o desenvolvimento destas crianças, principalmente a enfermagem, focando em suas deficiências e elaborando estratégias para combatê-las, pois um desenvolvimento comprometido gera conseqüências no futuro destas crianças.

Faz-se necessário, portanto a realização de projetos de extensão universitária para trabalhar com as questões referentes ao desenvolvimento cognitivo e de socialização dessas crianças favorecendo assim o seu desenvolvimento pleno.

Assim, sugere-se que outros estudos sobre a temática sejam incentivados com a finalidade de contribuir para a melhoria do cuidado a criança que vivencia seu crescimento e desenvolvimento no contexto de vulnerabilidade social do universo carcerário.

\section{Conflitos de interesses}

\footnotetext{
Nenhum conflito financeiro, legal ou político envolvendo terceiros (governo, empresas e fundações privadas, etc.) foi declarado para nenhum aspecto do trabalho submetido (incluindo mas não limitandose a subvenções e financiamentos, conselho consultivo, desenho de estudo, preparação de manuscrito, análise estatística, etc).
} 


\section{Referências}

Alexandre, D. T., \& Vieira, M. L. (2004). Relação de apego. Relação de apego entre crianças institucionalizadas que vivem em situação de abrigo. Psicologia em Estudo, 9(2), 207-217. Recuperado de http://www. scielo.br/pdf/pe/v9n2/v9n2a07.pdf

Araúio, C. L. P., Hallal, P. C., Nader, G. A., Menezes, A. M. B., \& Victora, C. G. (2008). Size at birth and height in early adolescence: a prospective birth cohort study. Cadernos de Saúde Pública, 24(4), 871-878, Recuperado de http://www.scielo.br/ pdf/csp/v24n4/18.pdf. doi: 10.1590/s0102$311 \times 2008000400018$

Barbosa, H. H. J. (2017). Sentido de número na infância: uma interconexão dinâmica entre conceitos e procedimentos. Paidéia, 17(37), 181-194, 2007. Recuperado de http://www.scielo.br/pdf/paideia/ v17n37/a03v17n37.pdf. doi: 10.1590/s0103$\underline{863 \times 2007000200003}$

Bardin, L. (2011). Análise de conteúdo. São Paulo: Edições 70.

Bruscato, A. (2011). Creche na prisão: um direito das mães e crianças. Educação e cidadania, 13, 35-39. Recuperado de https://seer.uniritter.edu.br/index.php?journal $=$ educacaoecidadania\&page $=$ article $\& o p=-$ view\&path $\% 5 B \% 5 D=529$

Chaves, C. M. P., Lima, F. E. T., Mendonça, L. B. A., Custódio, I. L., \& Matias, E. O. (2013). Avaliação do crescimento e desenvolvimento de crianças institucionalizadas. Revista Brasileira de Enfermagem, 66(5), 668-74. Recuperado de http://www.scielo.br/pdf/reben/v66n5/05.pdf. doi: $10.1590 /$ S0034-71672013000500005

Hasson, M. E., \& Meleiro, A. M. A. S. (2003). Reflexões sobre a desestruturação familiar na criminalidade. In Rigonatti, P.S., Serafin, A.P., \& Barros, E.L. (Orgs.), Temas em psiquiatria forense e psicologia jurídica (pp. 79-104). São Paulo: Vetor.

Lei $n^{\circ} 11.942$ de maio de 2009. Dá nova redação aos arts. 14, 83 e 89 da Lei no 7.210, de 11 de julho de 1984 - Lei de Execução Penal, para assegurar às mães presas e aos recém-nascidos condições mínimas de assistência. Recuperado de http://www.planalto.gov. br/ccivil_03/_ato2007-2010/2009/lei/I1 1942.htm

Lei $n^{\circ}$ 9.394, de 20 de dezembro de 1996. Presidência da república. Estabelece as diretrizes e bases da educação nacional. Recuperado de http://www. planalto.gov.br/Ccivil_03/leis/L9394.htm
Magalhães, C. M. C., Costa, L. N., \& Cavalcante, L. I. C. (2011). Percepção de educadores de abrigo: o seu trabalho e a criança institucionalizada. Revista Brasileira de Crescimento e Desenvolvimento Humano, 21 (3), 818-831. Recuperado de http://pepsic. bvsalud.org/pdf/rbcdh/v2 ln3/08.pdf.

Ministério da Justiça. (2014). Departamento penitenciário nacional. Levantamento nacional de informações penitenciarias infopen mulheres. Brasília: Autor. Recuperado de http://www.justica.gov.br/noticias/ estudo-traca-perfil-da-populacao-penitenciariafeminina-no-brasil/relatorio-infopen-mulheres.pdf

Ministério da Saúde (2002). Secretaria de Políticas de Saúde. Departamento de atenção básica. Saúde da criança: acompanhamento do crescimento e desenvolvimento infantil. Brasília: Autor. Recuperado de http://bvsms.saude.gov.br/bvs/publicacoes/ crescimento_desenvolvimento.pdf

Oliveira, S. V., Próchno, C. C. S. C. (2010). A Vinculação Afetiva para Crianças Institucionalizadas à Espera de Adoção. Psicologia ciência e profissão, 30(1), 62-84. Recuperado de http://www.scielo.br/pdf/ pcp/v30n 1/v30n1 a06.pdf. doi: 10.1590/s141498932010000100006

Quintino, S. A. (2005). Creche na prisão feminina do Paraná - Humanização da pena ou intensificação do controle social do estado? (Dissertação de mestrado). Universidade Federal do Paraná. Curitiba, PR, Brasil. Recuperado de http://www.justica.gov.br/ seus-direitos/politica-penal/politicas-2/mulheres-1 / anexos-projeto-mulheres/creche-na-prisao-femininado-parana.pdf

Romani, S. A. M., \& Lira, P. I. C. (2004). Fatores determinantes do crescimento infantil. Revista Brasileira de Saúde Materno Infantil, 4(1), 15-23. Recuperado de http:// www.scielo.br/pdf/rbsmi/v4n 1 / 19978.pdf. doi: 10.1590/S1519-38292004000100002

Santos, L. (2000). Adoção ou abrigos de tipo ideal?. Serviço Social e Sociedade, $21(63), 76-93$.

Silverman, D. (2009). Interpretação de Dados Qualitativos: Métodos para análise de entrevistas, textos e interações. Porto Alegre: Artmed. 